Sachiyo Takeoka $\cdot$ Motoko Unoki $\cdot$ Yoshihiro Onouchi

Satoru Doi · Hiroshi Fujiwara • Akihiko Miyatake

Kimie Fujita • Ituro Inoue • Yusuke Nakamura

Mayumi Tamari

\title{
Amino-acid substitutions in the IKAP gene product significantly increase risk for bronchial asthma in children
}

Received: November 9, 2000 / Accepted: November 10, 2000

\begin{abstract}
The complex etiology of bronchial asthma (BA), one of the most common inflammatory diseases throughout the world, involves a combination of various genetic and environmental factors. A number of investigators have undertaken linkage and association studies to shed light on the genetic background of BA, but the genetic aspects of this disease are still poorly understood. In the course of a project to screen the entire human genome for single nucleotide polymorphisms (SNPs) that might represent useful markers for large-scale association analyses of common diseases and pharmacogenetic traits, we identified six SNPs within the gene encoding I- $\mathrm{KB}$-associated protein (IKAP), a regulator of the NF- $\mathrm{KB}$ signal pathway. Most of these SNPs were in linkage disequilibrium with each other. We observed a strong allelic association between BA in childhood and two of the SNP sites, T3214A (Cys1072Ser) and C3473T (Pro1158Leu); $P=0.000004$ for T3214A and $P=$
\end{abstract}

S. Takeoka $\cdot$ M. Unoki $\cdot$ Y. Onouchi $\cdot$ Y. Nakamura $(\bowtie) \cdot$

M. Tamari

Laboratory of Molecular Medicine, Human Genome Center, The

Institute of Medical Science, The University of Tokyo, 4-6-1

Shirokanedai, Minato-ku, Tokyo 108-8639, Japan

Tel. +81-3-5449-5372; Fax +81-3-5449-5433

e-mail: yusuke@ims.u-tokyo.ac.jp

S. Takeoka

Fourth Department of Internal Medicine, Tokyo Women's Medical

University, Tokyo, Japan

S. Doi

Department of Pediatric Allergy, Osaka Prefectural Habikino

Hospital, Osaka, Japan

H. Fujiwara

Fifth Department of Internal Medicine, Osaka Prefectural Habikino Hospital, Osaka, Japan

A. Miyatake

Miyatake Asthma Clinic, Osaka, Japan

K. Fujita

College of Nursing, University of Shiga, Shiga, Japan

I. Inoue

Division of Genetic Diagnosis, The Institute of Medical Science, The

University of Tokyo, Tokyo, Japan
0.0009 for C3473T. T3214A was also associated with BA in adult patients $(P=0.000002)$, but $\mathrm{C} 3473 \mathrm{~T}$ was not $(P=$ 0.056). To confirm the above results, we compared estimated frequencies of haplotypes of the six SNPs between BA patients and controls. We found a strong association between $\mathrm{BA}$ in childhood and a specific haplotype, TGAAAT, that involved two amino-acid substitutions (819T, 2295G, 2446A, 2490A, 3214A, and 3473T; $P=$ 0.00004 , odds ratio, 2.94; $95 \%$ confidence interval [CI], 2.48-3.4). On the other hand, haplotype TACGTC, which differed from the TGAAAT haplotype in the last five nucleotides, was inversely correlated with the BA phenotype $(P=0.002$; odds ratio, 9.83 ; 95\% CI, 8.35-11.31). These results indicated that specific variants of the IKAP gene, or a variant in linkage disequilibrium with the TGAAAT haplotype, might be associated with mechanisms responsible for early-onset BA.

Key words Bronchial asthma - SNP · IKAP · Haplotype · Association study

\section{Introduction}

Bronchial asthma (BA), a disease characterized clinically by chronic, intermittent airway obstruction, with wheezing, coughing, and breathlessness, now affects $3 \%$ of adults and $6 \%$ of children in Japan. This complex disorder is considered to reflect a combination of various genetic and environmental factors. Many linkage and association studies have been performed with polymorphic DNA markers to disclose genetic components involved in the pathogenesis of BA. Manian (1997) reviewed studies showing linkage of atopy to chromosome 11, and linkage of atopy and bronchial hyperresponsiveness to chromosomes $5 \mathrm{q}$ and 12q. Others have suggested associations also between the BA phenotype and polymorphisms in the $\beta 2$ adrenoceptor (Hopes et al. 1998), tumor necrosis factor (TNF; Moffatt and Cookson 1997), platelet-activating factor (Stafforini et al. 1999), granulocyte/macrophage-colony stimulating fac- 
tor (Rohrbach et al. 1999), and interleukin 4 receptor (Ober et al. 2000), among others.

Genome-wide screenings for susceptibilities to asthma and atopy have highlighted several additional candidate regions (Manian et al. 1997). One such locus is at chromosome 9q, where Wjst et al. (1999) have mapped a locus linked to BA susceptibility $(P=0.0073)$, elevated serum immunogloblin E (IgE; $P=0.0098)$, and positive radioallergosorbent tests (RAST; $P=0.0025$ ). Their study involved 97 German and Swedish families and included 415 persons and $156 \mathrm{sib}$ pairs. The gene encoding IKK complexassociated protein (IKAP), which lies at 9q34, was considered to be a candidate for BA on positional grounds.

Single-nucleotide polymorphisms (SNPs), the most frequent type of genetic variation in the human genome, represent useful markers for association studies of common diseases and pharmacogenetic traits (Brookes 1999, Cargill et al. 1999, Evans and Relling 1999). To investigate possible associations of alleles at SNP sites with complex diseases such as BA, ischemic heart disease, and rheumatoid arthritis, we recently started a program to screen SNPs on a genome-wide scale (Ohnishi et al. 2000, Unoki et al. 2000, Yamada et al. 2000), bearing in mind that haplotype analysis of multiple SNPs is especially powerful for investigating alleles responsible for genetically complex diseases (Stephens et al. 1998, Tishkoff et al. 2000). Indeed, disorders such as Alzheimer disease and hypertension have been intensively analyzed in this way already (Jeunemaitre et al. 1997, Martin et al. 2000).

In the study reported here, we performed extensive screening of $I K A P$ by direct sequencing to detect alleles at polymorphic sites that might be responsible for BA. We identified six distinct SNPs in the coding region of the $I K A P$ gene, and identified allelic associations between BA and these SNPs. Further, we defined an association between a specific six-SNP haplotype and BA of childhood onset.

\section{Methods}

\section{Subjects}

Peripheral blood was obtained, with written informed consent, from each of 235 pediatric BA outpatients at the Osaka Prefectural Habikino Hospital (mean age, 9.57 years; range, 1-17 years; male/female ratio, 1.47:1.0; mean serum
IgE level, $1005.9 \mathrm{U} / \mathrm{ml})$. Most of these children had been diagnosed with atopic asthma. A total of 270 adult BA patients were also studied, 103 from the Internal Medicine Unit at the Osaka Prefectural Habikino Hospital and 167 from the Miyatake Asthma Clinic (mean age, 45.9 years; range, 18 to 83 years; male/female ratio, 1.0:1.16). Of the adult patients, $20 \%$ were atopic, but serum IgE levels were not available. As controls we analyzed 372 randomly selected, population-based individuals. Adult BA patients who reported episodes of asthma in childhood were excluded from the study. All patients had been diagnosed with BA according to the guidelines of the Japanese Society of Allergology, and disease status was classified into four categories: (1) no medication, (2) sodium chromoglycate (DSCG) and/or theophyline, (3) inhaled glucocorticoid, less than $400 \mu \mathrm{g} / \mathrm{day}$; and (4) inhaled glucocorticoid, more than $400 \mu \mathrm{g} / \mathrm{day}$. cDNAs were obtained from 51 volunteer individuals according to standard protocols, and genomic DNAs were prepared from all participants according to standard protocols. SNPs were screened according to methods we described previously (Ohnishi et al. 2000). This study was approved by the Institutional Review Board (IRB) of the Institute of Medical Science, The University of Tokyo.

\section{Screening for polymorphisms}

Eight primer sets (Table 1) were designed on the basis of the IKAP cDNA sequence available from GenBank (accession number, AF044195), so as to screen the entire coding region. Each polymerase chain reaction (PCR) was performed with 40 ng of mixed cDNA from three individuals. Reaction volumes of $50 \mu \mathrm{l}$ contained dNTPs $(25 \mathrm{mM})$, $\mathrm{MgCl} 2(6.68 \mathrm{mM}), 16.6 \mathrm{mM} \mathrm{NH} 4 \mathrm{SO} 4,6.7 \mathrm{mM}$ TrisHCl (pH 8.8), $10 \mathrm{mM} \beta$-mercaptoethanol, two sets of primers (F1 and R4, and F4 and R8, 50 pmol each), and Ex-Taq (2.5U; TaKaRa, Otsu, Japan). Samples were amplified in the GeneAmp PCR system 9600 (PE Applied Biosystems, Norwalk, CT, USA). Thermal-cycling conditions were $94^{\circ} \mathrm{C}$ for $2 \mathrm{~min}$; then 36 cycles of $94^{\circ} \mathrm{C}$ for $30 \mathrm{~s}, 56^{\circ} \mathrm{C}$ for $30 \mathrm{~s}$, and $72^{\circ} \mathrm{C}$ for $30 \mathrm{~s}$, with final extension at $72^{\circ} \mathrm{C}$ for $10 \mathrm{~min}$. Then each PCR product was reacted with BigDyeTM Terminator RR mix (PE Applied Biosystems) and one internal primer from among the 16 listed in Table 1. Sequences obtained in an ABI Prism 377 DNA autosequencer (PE Applied Biosystems) were assembled, and polymorphisms were identified by the Polyphred program (Nickerson et al. 1997).

Table 1. Primers used in screening for SNPs

\begin{tabular}{llll}
\hline F1 & GTACTGTTCTCGTGGGAATCACTT & $\mathbf{R 1}$ & CTTCTGATCCATGGAACTGTGTC \\
$\mathbf{F 2}$ & ACTGTTGGATGGGGTAGGAAG & $\mathbf{R 2}$ & CCACAGGTGCTGAAGGATAAACT \\
$\mathbf{F 3}$ & GGAAACTATCACTGGTATCTCAAGC & $\mathbf{R 3}$ & ATCCAAGTGAGAAGGCCTAGTT \\
$\mathbf{F 4}$ & TGAAGATCAAGATGTAAACCCG & $\mathbf{R 4}$ & CCGGCCTGTAATGTTTTAAATG \\
$\mathbf{F 5}$ & CCATACCTGCCAGTGTTTTG & $\mathbf{R 5}$ & CATGAGATGTAAGTATGGATAGGCA \\
$\mathbf{F 6}$ & GGATCCTGACGGGAATAAAATAG & $\mathbf{R 6}$ & ACATGTGAGAAAGGCTGAGAGAG \\
$\mathbf{F 7}$ & ACAACAGTACCAGGATATCAGCA & $\mathbf{R 7}$ & GGAGTATTTGCCACTCATCTCAC \\
$\mathbf{F 8}$ & GCAGGTCTGGATGATGAGGTA & $\mathbf{R 8}$ & TGAGTGGAAATGGTCTTCTCTGT
\end{tabular}

SNP, Single nucleotide polymorphism 


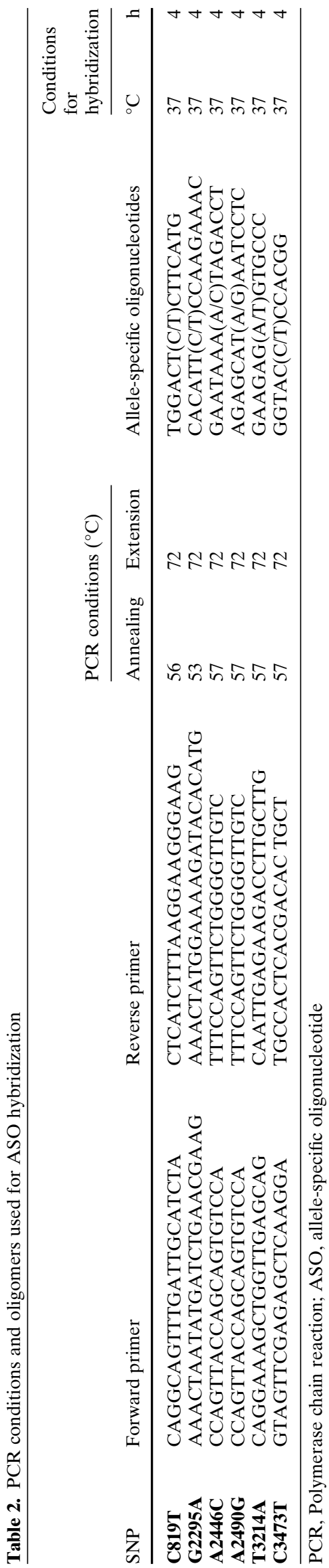

Amplification and genotyping of samples

All genomic DNA samples were amplified in the GeneAmp PCR system 9600 (PE Applied Biosystems), using primers designed so that each PCR product would include one or two SNPs. Conditions for thermal cycling and hybridization appear in Table 2. The PCR products were dot-blotted and fixed by UV-crosslinking on Biodyne membranes (PALL; Northern Boulevard East Hills, NY, USA) according to the manufacturer's protocol, then hybridized with ${ }^{32} \mathrm{P}$-labeled allele-specific oligonucleotide (ASO) sequences. For the C3473T locus, restriction fragment length polymorphism (RFLP) analysis/ PCR was performed on the same materials to confirm the ASO results. Each reaction mixture contained $10 \mu$ of PCR

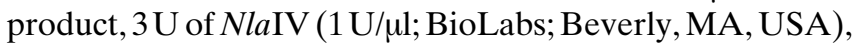
$2 \mu \mathrm{l}$ of $10 \mathrm{x}$ Buffer $\mathrm{K}$ (TaKaRa), and $15 \mu \mathrm{l}$ of $0.01 \%$ bovine serum albumin (BSA; TaKaRa). After $1 \mathrm{~h}$ of incubation at $37^{\circ} \mathrm{C}$, the products were electrophoresed on $2 \%$ agarose gels.

Statistical analysis

Allele frequencies in BA cases and controls were compared by the contingency $\chi^{2}$ test, using StatView-J 4.02 software (Abacus Concepts, Berkeley, CA, USA). Odds ratios were estimated according to Brown (1981). Phase-unknown samples, including 207 from controls, 235 from children with BA, and 90 from adult BA patients, were subjected to haplotype analysis, based on a maximum-likelihood method, using ARLEQUIN software Ver.2.0 (Genetics and Biometry Laboratory, Department of Anthropology, University of Geneva, Geneva, Switzerland). Haplotype frequencies between cases and controls were evaluated by $\chi^{2}$ tests in which the test of homogeneity was made with one degree of freedom rather than a global test with multiple degrees of freedom. Instead, probability values were corrected for multiple comparisons by multiplying the $P$ value by the number of haplotypes compared (Bonferroni adjustment). In addition, pairwise linkage disequilibrium coefficients were calculated and expressed as the $\mathrm{D}^{\prime}=\mathrm{D} / \mathrm{Dmax}$ or D/Dmin, according to Thompson et al. (1988).

\section{Results}

We screened the $I K A P$ gene for genetic variations among 51 Japanese subjects and identified six SNPs within the coding region: T819C (Leu273Leu), G2295A (Gly765Gly), A2446C (Ile816Leu), A2490G (Ile830Met), T3214A (Cys1072Ser) and C3473T (Pro1158Leu). Their locations are shown in Fig. 1. Leu273Leu is a silent substitution located in the WD-like repeats. Ile244Leu and Ile2490Met are in the IKK $\alpha$ binding site, and Cys3214Ser is in IKK $\alpha /$ IKK $\beta$ binding sites; Pro3473Leu lies in the serine-rich domain. Although two of these polymorphisms are silent changes, the four nonsynonymous substitutions would create missense alterations in the protein product.

Subsequently we performed an association study using these SNPs against the BA phenotype. All six of these loci 


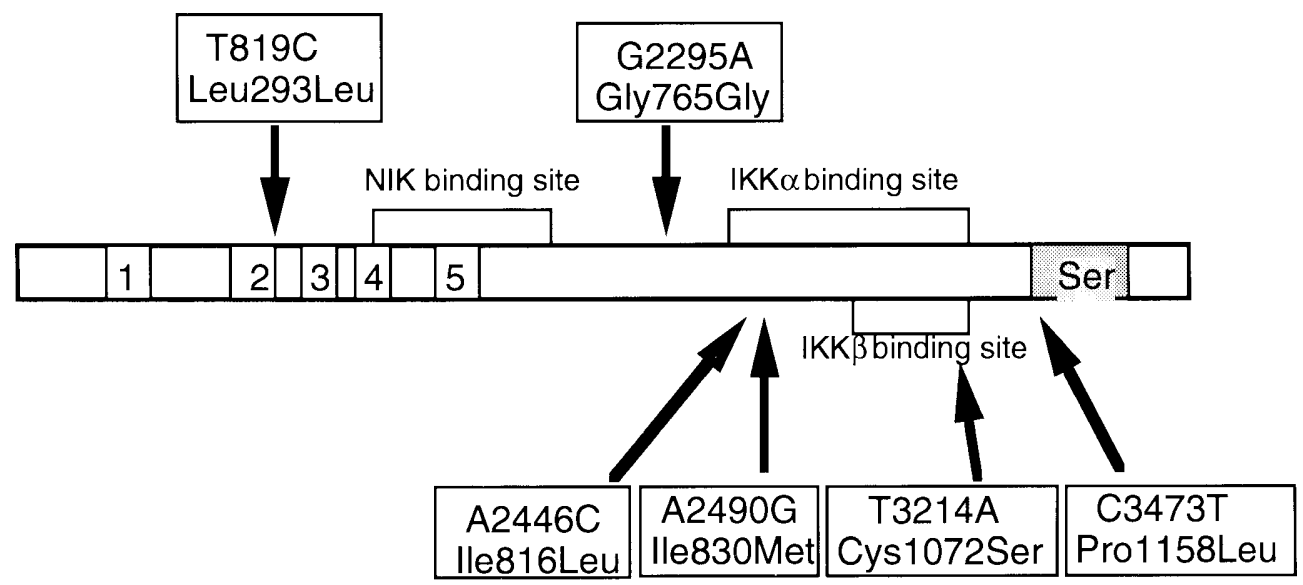

Fig. 1. Locations of six single nucleotide polymorphisms (SNPs) in the $I K A P$ gene. Five WD-like repeats are numbered, and binding sites for NIK and two IKKs are indicated. The SNPs labeled above the bar are synonymous; those below the bar would cause missense substitutions in the protein. The bronchial asthma (BA)-associated T3214A polymor-

were in Hardy-Weinberg equilibrium in the control group. When pairwise linkage disequilibrium was examined between the IKAP SNPs (Table 3), most of the SNPs were in linkage disequilibrium with each other. In particular, G2295A-A2490G and T3214A-C3473T showed quasicomplete linkage disequilibrium $\left(\mathrm{D}^{\prime}=0.966, \chi^{2}=124.0\right.$ and $\left.\mathrm{D}^{\prime}=0.884, \chi^{2}=256.1\right)$. The BA patients were divided into two groups according to age of onset (younger than 18, or 18 years and older); the younger than 18 years group (BA in childhood) represented atopic BA, and the over-18 group was rich in non-atopic BA. The six SNPs were examined in 235 pediatric BA samples and 266 adult BA samples, together with 294 controls, for comparisons of allelic frequencies (Table 4). In childhood BA we observed strong allelic associations with T3214A and C3473T $\left(\chi^{2}=16.29, \mathrm{df}=1, P\right.$ $=0.000004$ for T3214A, and $\chi^{2}=11.09$, df $=1, P=0.0009$ for C3473T). As already shown in Table 3, these two sites are associated strongly with each other. The T3214A allele was also associated with adult-onset $\mathrm{BA}\left(\chi^{2}=21.88, \mathrm{df}=1\right.$, $P=0.000002)$, but C3473T was not $\left(\chi^{2}=3.644, \mathrm{df}=1, P=\right.$ $0.056)$. The other four SNPs showed no association with BA, either in children or adults. When BA patients were further subdivided by severity according to the guidelines of the Japanese Society of Allergology, these SNPs failed to detect any differences regarding clinical severity (data not shown). These results indicated that Ser at codon 1072 and Leu at codon 1158 of the IKAP gene, or another genetic variant in strong association with these two substitutions, may have an important role in the etiology of BA, particularly BA of early onset.

Estimated frequencies of the six-locus haplotypes were compared between BA in childhood and controls, and between adult-onset BA patients and controls (Table 5). Although 26 different haplotypes were observed in the test population, 9 predominant haplotypes (frequency, more than $1 \%$ in controls) reflected linkage disequilibrium. Because the 17 minor haplotypes were combined as "others" (see Table 5), the estimated $P$ values were adjusted by phism lies in the IKK $\alpha$ and IKK $\beta$ binding domain, and the C3473T polymorphism lies within the region encoding a serine-rich domain. Leu, Leucine; Gly, glycine; Ser, serine; Ile, isoleucine; Met, methionine; Pro, proline; NIK, nuclear factor- $\mathrm{\kappa B}$-inducing kinase, $I K K ; \mathrm{I}-\kappa \mathrm{B}$ kinase

Table 3. Pairwise linkage-disequilibrium coefficients between six SNPs in control samples

\begin{tabular}{llllll}
\hline & \multicolumn{1}{l}{$\mathrm{D}^{\prime}$} & & & & \\
\cline { 2 - 6 } Polymorphism & T819C & G2295A & A2446C & A2490G & T3214A \\
\hline G2295A & 0.403 & - & - & - & - \\
A2446C & 0.308 & 0.735 & - & - & - \\
A2490G & 0.485 & 0.966 & 0.696 & - & - \\
T3214A & 0.103 & 0.344 & 0.33 & -0.943 & - \\
C3473T & 0.14 & 0.371 & 0.341 & -0.686 & 0.884 \\
\hline
\end{tabular}

Disequilibrium is expressed as $\mathrm{D}^{\prime} / \mathrm{Dmax}$ or Dmin, according to Thompson et al. (1988)

multiplying the number of haplotypes tested (Bonferroni adjustment). The most common haplotype was 819T, 2295G, 2446A, 2490A, 3214T, and 3473C (TGAATC) in all groups. A strong association with BA in childhood was observed with a TGAAAT haplotype $\left(\chi^{2}=22.34\right.$; df, 1 ; $P=0.00004$; odds ratio, 2.94; 95\% CI, 2.48-3.4; Table 5), in which two amino-acid substitutions were present (1072 from Cys to Ser and 1158 from Pro to Leu). However, a TACGTC haplotype, in which the last five nucleotides differed from the TGAAAT haplotype, was very uncommon in BA in childhood and was inversely correlated with the BA phenotype $\left(\chi^{2}=13.65 ; \mathrm{df}, 1 ; P=0.002\right.$; odds ratio, 9.83; 95\% CI, 8.35-11.31). The relative risk for BA among individuals bearing the TGAAAT haplotype is therefore nearly 25 times higher than that for those individuals carrying the TACGTC haplotype $\left(\chi^{2}=23.38\right.$; df, 1 ; odds ratio, 25.12; 95\% CI, 23.56-26.68).

\section{Discussion}

Currently available techniques have been unveiling the molecular etiologies of many human diseases at a rapid pace, especially those of monogenic origin. However, eluci- 
Table 4. Result of genotyping on the six SNPs

\begin{tabular}{|c|c|c|c|c|c|c|c|c|c|c|}
\hline & Control & Percentage & $\begin{array}{l}\text { Childhood } \\
\text { BA }\end{array}$ & Percentage & $\begin{array}{l}\chi^{2} \\
(\mathrm{df}=1)\end{array}$ & $P$ & $\begin{array}{l}\text { Adult } \\
\text { BA }\end{array}$ & Percentage & $\begin{array}{l}\chi^{2} \\
(\mathrm{df}=1)\end{array}$ & $P$ \\
\hline $\begin{array}{r}\text { Allele } \\
\text { T819C }\end{array}$ & $n$ & & $n$ & & & & $n$ & & & \\
\hline $\mathrm{T}$ & 553 & 82.5 & 376 & 80 & 1.179 & 0.277 & 425 & 83.7 & 0.259 & 0.618 \\
\hline $\mathrm{C}$ & 117 & 17.5 & 94 & 20 & & & 83 & 16.3 & & \\
\hline Total & 670 & & 470 & & & & 508 & & & \\
\hline \multicolumn{11}{|l|}{ G2295A (Gly765Gly) } \\
\hline G & 374 & 68.8 & 339 & 72.1 & 1.378 & 0.24 & 317 & 70.4 & 0.334 & 0.563 \\
\hline A & 170 & 31.2 & 131 & 27.9 & & & 133 & 29.6 & & \\
\hline Total & 544 & & 470 & & & & 450 & & & \\
\hline \multicolumn{11}{|l|}{ A2446C (Ile816Leu) } \\
\hline A & 466 & 73.7 & 337 & 71.7 & 0.563 & 0.453 & 353 & 93.4 & 0.002 & 0.965 \\
\hline $\mathrm{C}$ & 166 & 26.3 & 133 & 28.3 & & & 125 & 6.6 & & \\
\hline Total & 632 & & 470 & & & & 378 & & & \\
\hline \multicolumn{11}{|l|}{ A2490G (Ile830Met) } \\
\hline A & 550 & 87 & 417 & 88.7 & 0.723 & 0.395 & 458 & 88.4 & 0.509 & 0.475 \\
\hline $\mathrm{G}$ & 82 & 13 & 53 & 11.3 & & & 60 & 11.6 & & \\
\hline Total & 632 & & 470 & & & & 518 & & & \\
\hline \multicolumn{11}{|l|}{ T3214A (Cys1072Ser) } \\
\hline $\mathrm{T}$ & 438 & 74.5 & 296 & 63 & 16.291 & 0.000004 & 327 & 61.5 & 21.882 & 0.000002 \\
\hline $\mathrm{A}$ & 150 & 25.5 & 174 & 37 & & & 205 & 38.5 & & \\
\hline Total & 588 & & 470 & & & & 532 & & & \\
\hline \multicolumn{11}{|l|}{ C3473T (Pro1158Leu) } \\
\hline $\mathrm{C}$ & 529 & 71.1 & 291 & 61.9 & 11.091 & 0.0009 & 357 & 66.1 & 3.644 & 0.056 \\
\hline $\mathrm{T}$ & 215 & 28.9 & 179 & 38.1 & & & 183 & 33.9 & & \\
\hline Total & 744 & & 470 & & & & 540 & & & \\
\hline
\end{tabular}

BA, Bronchial asthma; df, degree of freedom

dation of the genetic basis of common diseases such as essential hypertension, diabetes mellitus, obesity, and asthma, is a major challenge in human genetics because their multifactorial etiologies involve both genetic and environmental factors. Among diseases of this type, bronchial asthma (BA) is probably the condition most extensively investigated so far. Genome-wide linkage studies of atopic asthma performed by numerous investigators in a variety of populations have detected several candidate regions, and allelic-association studies have been undertaken with candidate genes, such as $\beta 2$ adrenoceptor (Hopes et al. 1998), tumor necrosis factor (TNF) (Li Kam Wa et al. 1999), platelet-activating factor (Stafforini et al. 1999), granulocyte/macrophage-colony stimulating factor (Rohrbach et al. 1999), and interleukin 4 receptor (Ober et al. 2000). Another locus implicated in BA lies on chromosome 9q (Wjst et al. 1999).

Transcription factors belonging to the nuclear factor$\kappa \mathrm{B}(\mathrm{NF}-\kappa \mathrm{B})$ family are critical regulators of genes involved in inflammation, cell proliferation, and apoptosis. NF- $\kappa B$ is inactivated by binding to $\mathrm{I}-\kappa \mathrm{B}$, and activated through phosphorylation of I-אB. IKAP (IKK complex-associated protein) is a scaffold protein of the I- $\kappa \mathrm{B}$ kinase complex that consists of NF- $\kappa B$-inducing kinase (NIK), I- $\kappa B$ kinase (IKK)- $\alpha$, and IKK- $\beta$. Therefore IKAP is regarded as a regulator of at least three different kinases involved in the proinflammatory NF- $\mathrm{KB}$ signaling pathway (Cohen et al. 1998, Mercurio et al. 1999), and it seemed to be a likely candidate for association with BA. The IKAP gene lies on chromosome 9q34, where Wjst et al. (1999) mapped a locus linked to BA susceptibility $(P=0.0073)$, elevated serum immunogloblin $\mathrm{E}(\mathrm{IgE} ; P=0.0098)$, and positive radio- allergosorbent tests (RAST; $P=0.0025$ ) using DNA samples from 97 German and Swedish families that included 415 persons and 156 sib pairs. Interleukin 1 (IL-1), $\mathrm{TNF} \alpha$, leukotriene B4, and other physical-stress factors, such as exposure to allergens, can activate IKKs; in that case, NF- $\mathrm{KB}$ signaling via $\mathrm{I}-\mathrm{\kappa B}$ stimulates the production of pro-inflammatory mediators such as IL-1 $\beta$, IL-2, IL-6, IL-8, and IL-12. All these molecules are likely to be involved in the inflammatory processes of asthma. On the basis of mapping information and the other cited evidence, we assumed that $I K A P$ would be a likely candidate for some important role in the pathogenesis of BA.

We genotyped BA patients and control individuals for the six SNP sites present in the coding region of the IKAP gene, and detected a strong allelic association between BA in childhood and T3214A (Cys1072Ser) and C3473T (Pro1158Leu) polymorphisms $(P=0.000004$ for T3214A and $P=0.0009$ for C3473T as compared with controls). A strong association was also observed between adult-onset BA and T3212A, but not C3473T. The evidence of allelic association suggests an etiological role of IKAP in BA, especially BA of early onset. BA in childhood is often associated with atopy and allergenic load derived from house dust, mites, and pollen, and about $90 \%$ of child/juvenile patients have elevated serum IgE levels (Woolcock and Peat, 1997). Some genetic and environmental aspects, as they relate to differences in adult or childhood forms of BA, have been recorded elsewhere (Hopes et al. 1998). The juvenile BA patients who participated in this study presented elevated serum IgE and almost all cases were diagnosed as atopic asthma. Most of the adult BA patients recruited for the present study were nonatopic, because we 


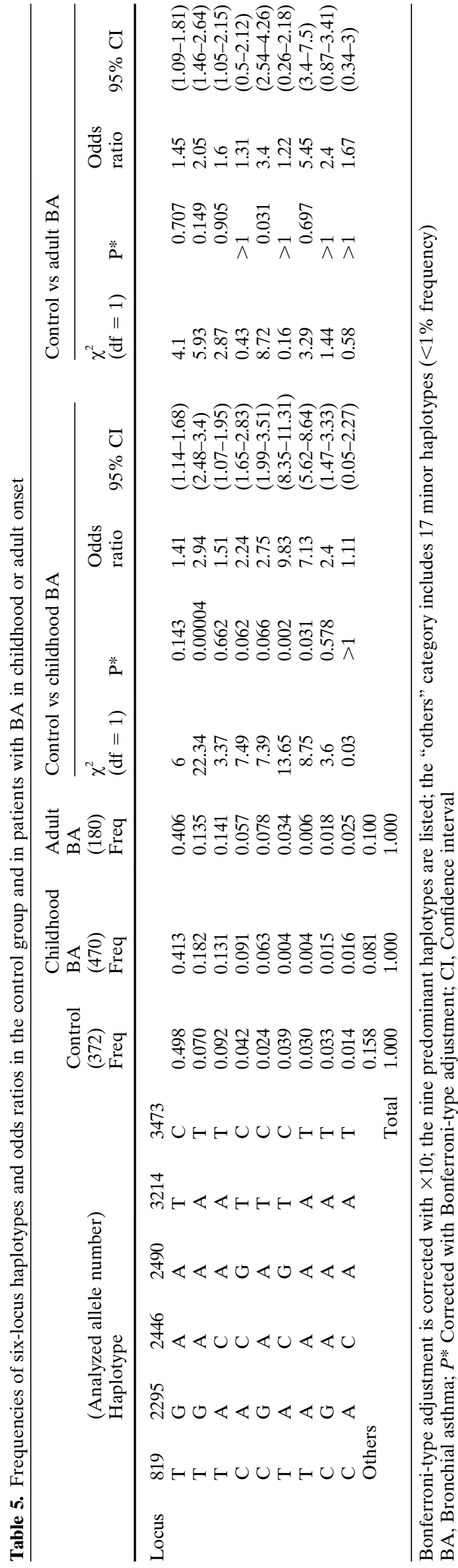

excluded patients who reported episodes of BA in childhood. Because we observed a positive association between adult-onset BA and the T3214A allele but not C3473T, probably an admixture of atopic and nonatopic phenotypes was present in this group.

Because the polymorphisms identified here as associated with $\mathrm{BA}$ in childhood occurred within the coding region of $I K A P$ and substituted Cys for Ser in the IKKs binding site and/or Leu for Pro in the serine-rich domain of the protein, it is possible that these alterations, singly or together, affect the signaling pathway by modifying the activity of IKAP. Alternatively, base substitution(s) elsewhere in this gene, i.e., in the promoter region or in introns, might account for susceptibility to BA by affecting the quality or quantity of the IKAP product, or another genetic variant in nearby gene(s) in strong linkage disequilibrium with these substitutions might have an important role in the etiology of BA.

When we combined multiple SNP sites and analyzed haplotypes, we observed only nine predominant haplotypes, because all six SNPs in the IKAP gene were in linkage disequilibrium with each other to various degrees (Table 5). We detected significant associations of the haplotype TGAAAT (odds ratio, 2.94; 95\% CI, 2.48-3.4) and haplotype TACGTC (odds ratio, 9.83; 95\% CI, 8.35-11.31), with BA in childhood-onset BA but not in the adult form. Because the TACGTC haplotype is more frequently present in controls, it could be interpreted as a protective or resistant allele. Therefore the relative risk of BA for individuals bearing haplotype TGAAAT is nearly 25 times higher than that for those individuals carrying haplotype TACGTC $\left(\chi^{2}=23.38\right.$; df, 1 ; odds ratio, $25.12 ; 95 \%$ CI, 23.56-26.68). Because the TGAAAT haplotype is associated with two amino-acid substitutions, i.e., in the IKK- $\beta$ binding domain and in the serine-rich domain of IKAP, an allele with this haplotype might alter the role of IKAP as a scaffold protein, accelerating or decelerating the signaling of NF-kB. To fully understand the effects of IKAP SNPs on the asthma phenotype, especially in childhood, it may be desirable in future studies to investigate the relationship between genotypes and the functional role of the SNPs in this gene.

Acknowledgments We thank all patients and their families, the volunteers who served as controls, and all staff members at the Osaka Prefectural Habikino Hospital and the Miyatake Asthma Clinic who assisted in this study. We also thank Dr. Toshiaki Nakajima for helping with haplotype analysis, Ms. Rie Hayashi and Ms. Maiko Minami for technical assistance, and Ms. Yuria Mano for skillful extraction of DNA from the large number of blood samples.

\section{References}

Brookes AJ (1999) The essence of SNPs. Gene 234:177-186

Brown CC (1981) The validity of approximation methods for interval estimation of the odds ratio. Am J Epidemiol 113:474-480

Cargill M, Altshuler D, Ireland J, Sklar P, Ardlie K, Patil N, Lane CR, Lim EP, Kalyanaraman N, Nemesh J, Ziaugra L, Friedland L, Rolfe A, Warrington J, Lipshutz R, Daley GQ, Lander ES (1999) Characterization of single-nucleotide polymorphisms in coding regions of human genes. Nature Genet 22:231-238 
Cohen L, Henzel WJ, Baeuerle PA (1998) IKAP is a scaffold protein of the IкB kinase complex. Nature 395:292-296

Evans WE, Relling MV (1999) Pharmacogenomics: translating functional genomics into rational therapeutics. Science 286:487-491

Hopes E, McDougall C, Christie G, Dewar J, Wheatly A, Hall IP, Helms PJ (1998) Association of glutamine 27 polymorphism of $\beta 2$ adrenoceptor with reported childhood asthma: population based study. BMJ 316:664

Jeunemaitre X, Inoue I, Williams C, Charru A, Tichet J, Powers M, Sharma AM, Gimenez-Roqueplo AP, Hata A, Corvol P, Lalouel JM (1997) Haplotypes of angiotensinogen in essential hypertension. Am J Hum Genet 60:1448-1460

Li Kam Wa TC, Mansur AH, Britton J, Williams G, Pavord I, Richard K, Campbell DA, Morton N, Holgate ST, Morrison JF (1999) Association between -308 tumour necrosis factor promoter polymorphism and bronchial hyperreactivity in asthma. Clin Exp Allergy 29:1204-1208

Manian P (1997) Genetics of asthma: a review. Chest 112:1397-1407

Martin ER, Lai EH, Gilbert JR, Rogara AR, Afshari AJ, Riley J, Finch KL, Stevens JF, Livak KJ, Slotterbeck BD, Slifer SH, Warren LL, Conneally PM, Schmechel DE, Purvis I, Pericak-Vance MA, Roses AD, Vance JM (2000) SNPing away at complex diseases: analysis of single-nucleotide polymorphisms around APOE in Alzheimer disease. Am J Hum Genet 67:383-394

Mercurio F, Murray BW, Shevchenko A, Bennett BL, Young DB, Li JW, Pascual G, Motiwala A, Zhu H, Mann M, Manning AM (1999) IkappaB kinase (IKK) - associated protein 1, a common component of the heterogeneous IKK complex. Mol Cell Biol 19:15261538

Moffatt MF, Cookson WO (1997) Tumour necrosis factor haplotypes and asthma. Hum Mol Genet 6:551-554

Nickerson DA, Tobe VO, Taylor SL (1997) Polyphred: automating the detection and genotyping of single nucleotide substitution using fluorescence-based resequencing. Nucleic Acids Res 25:2745-2751

Ober C, Leavitt AS, Tsalenko A, Howard DT, Hok MD, Daniel R, Newman LD, Wu X, Parry R, Lester AL, Solway J, Blumenthal M, King AR, Xu J, Meyers AD, Bleecker RE, Cox JN (2000) Variation in the interleukin 4-receptor $\alpha$ gene confers susceptibility to asthma and atopy in ethnically diverse populations. Am J Hum Genet 66:517-526

Ohnishi Y, Tanaka T, Yamada R, Suematsu K, Minami M, Fujii K, Hoki N, Kodama K, Nagata S, Hayashi T, Kinoshita N, Sato H, Sato H, Kuzuya T, Takeda H, Hori M, Nakamura Y (2000) Identification of 187 single nucleotide polymorphisms (SNPs) among 41 candidate genes for ischemic heart disease in the Japanese population. Hum Genet 106:288-292

Rohrbach M, Frey U, Kraemer R, Liechti-Gallati S (1999) A variant in the gene for GM-CSF, I117T, is associated with atopic asthma in a Swiss population of asthmatic children. J Allergy Clin Immunol 104:247-248

Stafforini DM, Numao T, Tsodikov A, Vaitkus D, Fukuda T, Watanabe N, Fueki N, McIntyre TM, Zimmermsn GA, Makino S, Prescott SM (1999) Deficiency of platelet-activating factor acetylhydrolase is a severity factor for asthma. J Clin Invest 103:989997

Stephens JC, Reich DE, Goldstein DB, Shin HD, Smith MW, Carrington M, Winkler C (1998) Dating the origin of the CCR5Delta32 AIDS-resistance allele by the coalescence of haplotypes. Am J Hum Genet 62:1507-1515

Thompson EA, Deeb S, Walker D, Motulsky AG (1988) The detection of linkage disequilibrium between closely linked markers: RFLPs at the AI-CIII apolipoprotein genes. Am J Hum Genet 42:113124

Tishkoff SA, Pakstis AJ, Ruano G, Kidd KK (2000) The accuracy of statistical methods for estimation of haplotype frequencies: an example from the CD4 locus. Am J Hum Genet 67:518-522

Unoki M, Furuta S, Onouchi Y, Watanabe O, Doi S, Fujiwara H, Miyatake A, Fujita K, Tamari M, Nakamura Y (2000) Association studies of 33 single nucleotide polymorphisms (SNPs) in 29 candidate genes for bronchial asthma: positive association of a T924C polymorphism in the thromboxane A2 receptor gene. Hum Genet 106:440-446

Wjst M, Fischer G, Immervoll T, Jung M, Saar K, Rueschendorf F, Reis A, Ulbrecht M, Gomolka M, Weiss EH, Jaeger L, Nickel R, Richter K, Kjellman NIM, Griese M, Berg A, Gappa M, Riedel F, Boehle M, Koningsbruggen S, Schoberth P, Szczepanski R, Dorsch W, Silbermann M, Loesgen S, Scholz M, Bickeboller H, Wichmann HE (1999) A genome-wide search for linkage to asthma. Genomics 58:18

Woolcock AJ, Peat JK (1997) Evidence for the increase in asthma worldwide. Ciba Found Symp 206:122-130

Yamada R, Tanaka T, Ohnishi Y, Suematsu K, Minami M, Seki T, Yukioka M, Maeda A, Murata N, Saiki O, Teshima R, Kudo O, Ishikawa K, Ueyoshi A, Tateishi H, Inaba M, Goto H, Nishizawa Y, Tohma S, Ochi T, Yamamoto K, Nakamura Y (2000) Identification of 142 single nucleotide polymorphisms in 41 candidate genes for rheumatoid arthritis in the Japanese population. Hum Genet 106:293-297 